\title{
Splitting the normal brain with reaction time ${ }^{1}$
}

R. A. FILBEY and M. S. GAZZANIGA, New York University, New York, N.Y. 10003

Two simple choice-reaction-time experiments were performed using tachistoscopic flashes containing a dot to the right or left of fixation or a blank field as stimuli. One experiment required a verbal response and the other a manual response to the presence or absence of a dot. Median verbal reaction times to a right dot averaged $386 \mathrm{msec}$, while those to a left dot or to a blank field averaged 419 and $420 \mathrm{msec}$, respectively. Median manual reaction times to a blank field averaged $382 \mathrm{msec}$, while those to a right or to a left dot averaged 336 and $341 \mathrm{msec}$. respectively. The $30-40 \mathrm{msec}$ differences are taken to be a reflection of callosal transmission time, that is, the delay required for the information received in one hemisphere to be acted upon by the other hemisphere.

The two cortical mantles of the human brain are normally richly interconnected across the midline by the corpus callosum. For years, it was supposed that this structure, the largest fiber system in the brain, served no important neurological or psychological function. During the last 2 decades, however, a variety of experimental studies on animals and also on man have delineated, with striking clarity, the role this interhemispheric commissure system plays in maintaining normal behavioral unity (Sperry, 1961, 1964; Gazzaniga, 1967, 1969). In brief, these "split-brain" studies have shown that the callosum is utterly responsible for such routine functions as relaying sensory and motor information present in the right hemisphere over to the left and vice versa. With it intact, one can verbally describe all visual events to the left or right of fixation, but with it sectioned, only those events falling into the right visual field, which projects directly to the left speech hemisphere, can be described. Events occurring to the left of fixation, thereby going to the right hemisphere, cannot be described-indeed, they go unneticed by the left hemisphere in the split-brain human.

With the new knowledge of what is not possible when a specific neural communication channel is absent, an important task is to study the system intact, with the aim of coming to a closer understanding of the logic and nature of the information-transmission mechanism.
The following experiments ate an attempt to delineate some of the characteristics of this information system.

\section{EXPERIMENT 1}

The strategy used in this experiment is to capitalize on the fact that usually only the left hemisphere is responsible for speech. Information presented directly to the left hemisphere ought to be reported sooner than that presented to the right hemisphere. The difference in reaction time between the two modes of stimulus presentation should reflect the time needed to transmit the information across the callosum.

\section{Method}

Eight right-handed female coeds were instructed, following the onset of a warning buzzer, to fixate a specific point in the visual field. Following the flash containing the stimulus, they were instructed to make a verbal response indicating the presence or absence of a dot as quickly as possible and without making an error. In brief, a dot or a blank was presented tachistoscopically for $0.1 \mathrm{sec}$, being preceded $1.5 \mathrm{sec}$ by a warning buzzer. The dot was presented either $1 \mathrm{deg}$ to the right or left of fixation. Half of the Ss were instructed to be "dot detectors," verbally responding "yes" to the presence of a dot and "no" to a blank. The remaining Ss were instructed to be "blank detectors," responding "yes" to a blank and "no" to a dot presentation. In 5 days of testing, three banks of 20 trials plus 4 warm-up trials were run each day. Each bank of 20 trials was broken up in to five blocks of four stimuli (blank, right dot, left dot, blank) that were block-randomized. Ss were given a 30-sec rest period between each bank of 20 trials. Each day of testing took about $20 \mathrm{~min}$ per $\mathrm{S}$. The onset of the test flash started a millisecond timer that was stopped by a voice-operated relay, triggered by the S's spoken word into a nearby crystal microphone. The elapsed

\begin{tabular}{|c|c|c|c|c|c|c|c|c|c|c|}
\hline \multirow[b]{2}{*}{ Ss } & \multirow{2}{*}{$\begin{array}{c}\text { Verbal } \\
\text { Response } \\
\text { to Dot }\end{array}$} & \multicolumn{3}{|c|}{ Right Dot } & \multicolumn{3}{|c|}{ Left Dot } & \multicolumn{3}{|c|}{ Blank } \\
\hline & & $\begin{array}{l}\text { Mean of } \\
\text { Medians }\end{array}$ & $\begin{array}{c}\text { Mean } \\
\text { SD }\end{array}$ & $\begin{array}{c}\% \\
\text { Error* }\end{array}$ & $\begin{array}{l}\text { Mean of } \\
\text { Medians }\end{array}$ & $\begin{array}{c}\text { Mean } \\
\text { SD }\end{array}$ & $\begin{array}{c}\% \\
\text { Error* }\end{array}$ & $\begin{array}{l}\text { Mean of } \\
\text { Medians }\end{array}$ & $\begin{array}{c}\text { Mean } \\
\text { SD }\end{array}$ & $\begin{array}{c}\% \\
\text { Error* }\end{array}$ \\
\hline MM & Yes & 438 & 37.3 & 3.2 & 482 & 35.8 & 3.2 & 458 & 50.1 & 0.0 \\
\hline DG & Yes & 342 & 51.8 & 0.0 & 388 & 64.3 & 0.0 & 419 & 64.1 & 0.0 \\
\hline NS & Yes & 284 & 40.0 & 0.0 & 337 & 52.0 & 0.0 & 368 & 51.6 & 0.0 \\
\hline SC & Yes & 565 & 76.3 & 0.0 & 569 & 62.7 & 3.2 & $\$ 92$ & 74.6 & 1.6 \\
\hline vs & No & 359 & 38.8 & 0.0 & 368 & 31.5 & 3.2 & 344 & 58.8 & 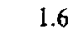 \\
\hline $\mathrm{CL}$ & No & 374 & 73.7 & 0.0 & 422 & 82.9 & 6.5 & 402 & 49.6 & 1.6 \\
\hline $\mathrm{CF}$ & No & 330 & 58.4 & 3.2 & 397 & 76.7 & 3.2 & 364 & 80.3 & 0.0 \\
\hline $\mathrm{TL}$ & No & 388 & 41.7 & 0.0 & 390 & 55.8 & 0.0 & 412 & 57.0 & 1.6 \\
\hline \multicolumn{2}{|c|}{ Average Over $S$} & Ss 386 & 52.2 & 0.8 & 419 & 57.7 & 2.4 & 420 & 60.8 & 0.8 \\
\hline
\end{tabular}

* Percentage computation does not include mock trials. time for each correct response was recorded. Corsect response times were also reported to the $S$ to keep motivation at a high level during the task. Error trial times were not included in the data nor were the following four mock trial times, although these latter times were reported to the $S$ as usual. These "mock" trials were inserted because it was found that, following an error, the S's next two or three reaction times were highly variable. Four mock trials were used to keep the stimuli counterbalanced.

\section{Results}

The results of the last 2 days of testing are tabulated in Table 1. Verbal responses to right dots were a little over $30 \mathrm{msec}$ faster than those for either left dots or blank fields. Table 2 shows these results to be significant.

\section{Discussion}

The data show that when a callosal transmission is necessary for either making the discrimination (as in the case of a blank presentation) or responding appropriately (as in the case of a dot appearing to the left of fixation), reaction times are slower by about an average of $30 \mathrm{msec}$. It could be argued that this difference is due to more peripheral perceptual variables (or to the right cortex simply not being as fast at this kind of task) rather than to the brain mechanisms outlined above. To investigate this criticism, the following study was performed.

\section{EXPERIMENT 2}

Method

Eight right-handed female Ss were used to replicate the previous experiment. Instead of giving a verbal response, however, they were instructed to give a manual response. This consisted of moving a lever to the right or left, depending on the stimulus. A small displacement of the lever to either side stopped the millisecond timer. Again, half of the Ss were instructed to be "dot detectors," moving the lever to the right if they saw a dot in the field and to the left if the field was blank. The remaining Ss were instructed to be "blank detectors," moving the lever to the right 
Table 2

Analysis of Variance for Experiment 1 (Verbal)

\begin{tabular}{llrrc}
\hline & Source & df & SS & F \\
\hline Between & B & 1 & 19953 & 1.12 \\
& Error & 6 & 106547 & - \\
Within & A & 2 & 6350 & $8.76^{*}$ \\
& AxB & 2 & 1361 & 1.88 \\
& Error & 12 & 4350 & - \\
\hline
\end{tabular}

* Significant at .05 level, 2-tailed F test. Treatment $A$ includes the right dot, left dot, and blank field stimuli conditions. Treatment $B$ includes the "dot detectors" vs "blank detec. tors" condition.

following a blank stimulus and to the left for the presence of a dot in the field. The Ss always responded with their right hands. Results

The results of the last 2 days of testing are given in Table 3. Manual responses to both right and left dots appear to be about equal in the pooled data, while those to blank fields average about $30 \mathrm{msec}$ slower. Table 4 shows these results to be significant.

\section{Discussion}

In previous studies, each hemisphere of a split brain has been shown to have good motor control over either half of the body (Gazzaniga, 1967). This being the case, the experiment using a motor response differs from the one using a verbal response in that, in the former, both hemispheres have access to the response without using the callosum, while in the latter, only the left hemisphere has access to the response. As before, however, a callosal transmission is necessary to determine whether or not the entire field was blank. If the results of the first experiment are merely due to peripheral perceptual variables or to right cortex inferiority in the task, the results of the second experiment should be identical to those of the first. Clearly, they are not. Using a motor response, reaction times both to a dot to the left and to a dot to the right of fixation show little difference, while reaction time to a blank field is, on the average, about $40 \mathrm{msec}$ longer. The data indicate that there exists an intercortical difference in reaction time during a visual discrimination.

One difficulty with the second experiment was the necessity to pool the

Table 3

\begin{tabular}{|c|c|c|c|c|c|c|c|c|c|c|}
\hline \multirow[b]{2}{*}{ Ss } & $\begin{array}{c}\text { Lever } \\
\text { Displaceme } \\
\text { Response }\end{array}$ & \multicolumn{3}{|c|}{ Right Dot } & \multicolumn{3}{|c|}{ Left Dot } & \multicolumn{3}{|c|}{ Blank } \\
\hline & $\begin{array}{c}\text { Response } \\
\text { to Dot }\end{array}$ & $\begin{array}{l}\text { Mean of } \\
\text { Medians }\end{array}$ & $\begin{array}{c}\text { Mean } \\
\text { SD }\end{array}$ & $\begin{array}{c}\% \\
\text { Error* }\end{array}$ & $\begin{array}{l}\text { Mean of } \\
\text { Medians }\end{array}$ & $\begin{array}{c}\text { Mean } \\
\text { SD }\end{array}$ & $\begin{array}{c}\% \\
\text { Error* }\end{array}$ & $\begin{array}{l}\text { Mean of } \\
\text { Medians }\end{array}$ & $\begin{array}{c}\text { Mean } \\
\text { SD }\end{array}$ & $\begin{array}{c}\% \\
\text { Error* }\end{array}$ \\
\hline $\mathbf{R}$ & Right & 252 & 57.6 & 0.0 & 232 & 47.8 & 0.0 & 284 & 58.4 & 0.0 \\
\hline $\mathbf{K}$ & Right & 374 & 61.3 & 3.2 & 420 & 37.8 & 0.0 & 448 & 72.9 & 1.6 \\
\hline SB & Right & 322 & 72.4 & 0.0 & 354 & 72.7 & 6.5 & 405 & 43.4 & 0.0 \\
\hline JH & Right & 364 & 54.0 & 3.2 & 418 & 71.1 & 0.0 & 430 & 74.5 & 10.0 \\
\hline L1 & Left & 218 & 65.5 & 3.2 & 272 & 59.6 & 6.5 & 334 & 80.6 & 4.8 \\
\hline $\mathrm{L} 2$ & Left & 394 & 73.8 & 0.0 & 352 & 61.2 & 3.2 & 394 & 89.0 & 1.6 \\
\hline JC & Left & 412 & 118.0 & 35.0 & 340 & 56.6 & 12.0 & 390 & 104.0 & 21.0 \\
\hline $\mathrm{CC}$ & Left & 348 & 76.6 & 12.0 & 338 & 68.3 & 0.0 & 369 & 75.0 & 3.2 \\
\hline \multicolumn{11}{|c|}{ Average } \\
\hline Ove & Ss & 336 & 72.4 & 10.0 & 341 & 59.4 & 3.6 & 382 & 74.7 & 8.4 \\
\hline
\end{tabular}

- Percentage computation does not include mock trials.

data across Ss. The manual response chosen was an unfortunate one in that there was considerable response competition (a right dot tended to elicit a right displacement regardless of the instructions, and vice versa). It was hoped that after the considerable amount of training that was given, this response competition would drop out, but unfortunately it did not. Perhaps a better response would have been lever displacements not spatially related to the stimuli, e.g., a displacement away from the $\mathbf{S}$ for one type of stimulus and toward the $S$ for the other.

An interesting aspect of the data is the magnitude of differences in reaction time between responses to visual information requiring transmission across the callosum and responses not requiring such transmission. The latency of synaptic transmission is only $.5 \mathrm{msec}$ while the differences reported here are in the 30 - to $40-\mathrm{msec}$ range. Clearly, the information crossing the callosum does not take the

Table 4

Analysis of Variance for Experiment 2 (Manual)

\begin{tabular}{llrrc}
\hline & Source & df & \multicolumn{1}{c}{ SS } & F \\
\hline Between & B & 1 & 852 & .073 \\
& Error & 6 & 69520 & - \\
Within & A & 2 & 10226 & $7.02^{*}$ \\
& AxB & 2 & 9316 & $6.34^{*}$ \\
& Error & 12 & 8734 & - \\
\hline
\end{tabular}

* Significant at .05 level, 2-tailed $F$ test. Treatment $A$ includes the right dot, left dot, and blank field stimuli conditions. Treatment $B$ inchudes the "dot detectors" vs "blank detectors" condition. form of one discrete signal or of several simultaneous signals alone. Information transmission for this type of task seems to require several successive signals over one or more neurons.

It remains for future research to explore the nature of these successive signals and to finally designate the actual routing of information within and between hemispheres during a visual-discrimination task like the one reported here. Furthermore, now that a base time has been established for callosal transmission in a very simple visual pattern-discrimination task, it remains to be discovered whether or not this callosal transmission time increases with the complexity of the discrimination. The answer to that question would give evidence as to the amount of processing that each side of the cortex does on the discrimination task, i.e., whether the callosal transmission is some sort of "go/no-go" message or an elaborate readout of raw visual information.

\section{REFERENCES}

GAZZANIGA, M. S. The split brain in man Scientific American, 1967, 217, 24-29.

GAZZANIGA, M. S. The bisected brain. New York: Appleton-Century-Crofts, in press.

SPERRY, R. W. Cerebral organization and behavior. Science, 1961, 133, 1749.

SPERRY, R. W. The great cerebral commissure.

Scientific American, 1964, 210, 42.

$$
\text { NOTE }
$$

1. Aided by USPHS MH 13289 awarded to M. S. Gazzaniga. 